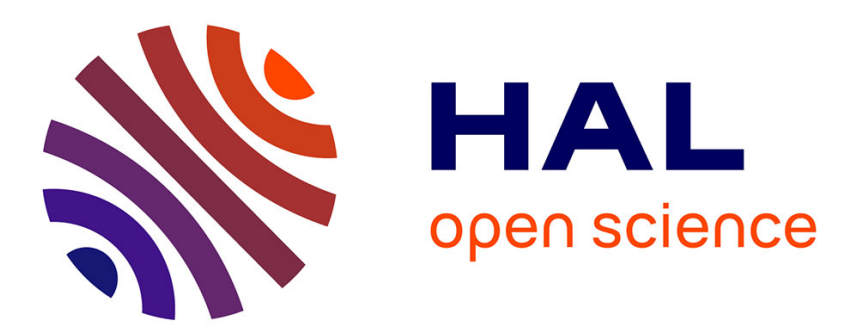

\title{
Collapsed bipolar glycolipids at the air/water interface: Effect of the stereochemistry on the stretched/bent conformations.
}

Alicia Jacquemet, Nolwenn Terme, Thierry Benvegnu, Véronique Vié, Loïc Lemiègre

\section{To cite this version:}

Alicia Jacquemet, Nolwenn Terme, Thierry Benvegnu, Véronique Vié, Loïc Lemiègre. Collapsed bipolar glycolipids at the air/water interface: Effect of the stereochemistry on the stretched/bent conformations.. Journal of Colloid and Interface Science, 2013, 412, pp.72-81. 10.1016/j.jcis.2013.09.010 . hal-00876528

\section{HAL Id: hal-00876528 \\ https://hal.science/hal-00876528}

Submitted on 6 Dec 2013

HAL is a multi-disciplinary open access archive for the deposit and dissemination of scientific research documents, whether they are published or not. The documents may come from teaching and research institutions in France or abroad, or from public or private research centers.
L'archive ouverte pluridisciplinaire HAL, est destinée au dépôt et à la diffusion de documents scientifiques de niveau recherche, publiés ou non, émanant des établissements d'enseignement et de recherche français ou étrangers, des laboratoires publics ou privés. 


\title{
Collapsed bipolar glycolipids at the air/water interface: Effect of the stereochemistry on the Stretched/Bent conformations
}

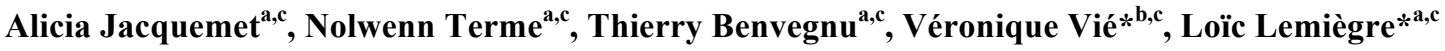 \\ ${ }^{a}$ Ecole Nationale Supérieure de Chimie de Rennes, CNRS, UMR 6226, 11 Allée de Beaulieu, \\ CS 50837, 35708 Rennes Cedex 7, France. \\ ${ }^{b}$ Institut de Physique de Rennes, Université Rennes 1, UMR-CNRS 6251, Campus Beaulieu \\ Bat. 11A, 35042 Rennes Cedex, France. \\ ${ }^{c}$ Université européenne de Bretagne, France.
}

Corresponding authors. Fax: +33223238046

loic.lemiegre@ensc-rennes.fr ; veronique.vie@univ-rennes1.fr

\begin{abstract}
This article describes a comparative study of several bipolar lipids derived from tetraether structures. The sole structural difference between the main two glycolipids is a unique stereochemical variation on a cyclopentyl ring placed in the middle of the lipids. We discuss the comparative results obtained at the air/water interface on the basis of tensiometry and ellipsometry. Langmuir-Blodgett depositions during lipid film compressions and decompressions were also analyzed by AFM. The lactosylated tetraether (bipolar) lipid structures involved the formation of highly stable multilayers, which are still present at 10 $\mathrm{mN} . \mathrm{m}^{-1}$ during decompression. This study suggests also that the stereochemistry of a central cyclopentyl ring dramatically drives the conformation of the corresponding bipolar lipids. Both isomers (trans and cis) adopt a U-shaped (bent) conformation at the air/water interface but the trans cyclopentyl ring induces a much more frustration within this type of conformation. Consequently, this bipolar lipid (trans-tetraether) undergoes a flip of one polar head-group (lactosyl) leading to a stretched conformation during collapse.
\end{abstract}

\section{Keywords}

Bipolar lipid; Bolaamphiphile; Glycolipid; Cyclopentyl ring; Stereochemistry; Langmuir film; AFM

\section{Introduction}

Multilayer or monomolecular lipid films are not only suitable systems to characterize interactions of biomimetic amphiphilic molecules but they are also involved in the production of nanotechnological devices for instance.[1-6] For this purpose a well-defined architecture (composition, structure, orientation and thickness) is required. Preforming monomolecular films at the air/liquid interface using a Langmuir trough allows fine understanding of film behavior by a precise control of physical parameters such as surface pressure and temperature. Multilayered films can result either of successive monolayer transfers on solid supports (Langmuir-Blodgett or Langmuir Schaeffer) or of spontaneous formation upon compressing beyond the collapse pressure before transfer. In addition to physical parameters, the structure of the amphiphiles studied at the air/water interface has a profound impact on the physical properties of the corresponding films. Among the lipid family, the case of bipolar lipids (bolaamphiphiles), which add a covalent bond between the two hydrophobic domains to conventional monopolar lipids, is of particular interest.[7-10] Indeed this type of structure enlarges the variety of possible applications.[7, 9] For instance during the past few years, our research group and others[11-17] has been involved in the synthesis of bipolar lipids with the aim to increase the efficiency of drug/DNA delivery systems[18-20] and to establish as far as possible the closest structure/property relationships.[19, 21-24] Most of synthetic bolaamphiphilic lipids prepared so far involved a single hydrophobic chain devoid of stereogenic centers, which limited the number of fundamental studies on the effect of stereochemical variations on the packing properties of such unconventional lipids.[8-10] However, the original bipolar tetraether lipids originating from archaea organisms[25-28] bear about 20 stereogenic centers that would play a role on the lipid packing properties within natural membranes or synthetic films. Indeed the tetraether lipids are usually (but not always) macrocyclic and based on isoprenoid chains including 0 to 8 cyclopentyl rings (Figure 1). They are known to be responsible for the remarkable stability and low permeability of archaeal lipid membranes under harsh conditions in terms of $\mathrm{pH}$ and 
temperature for instance.

Thus archaeal lipid analogues appear to be appropriate candidates for a fundamental study devoted to the determination of the impact of stereochemical variations on bipolar lipid packing. One question often asked when studying bipolar lipids is the ability of these lipids to adopt a stretched or a bent conformation as shown on figure 1 . Therefore, one can legitimately wonder how a single stereochemical variation would influence conformational preferences (stretched or bent) and global properties of corresponding lipid films.

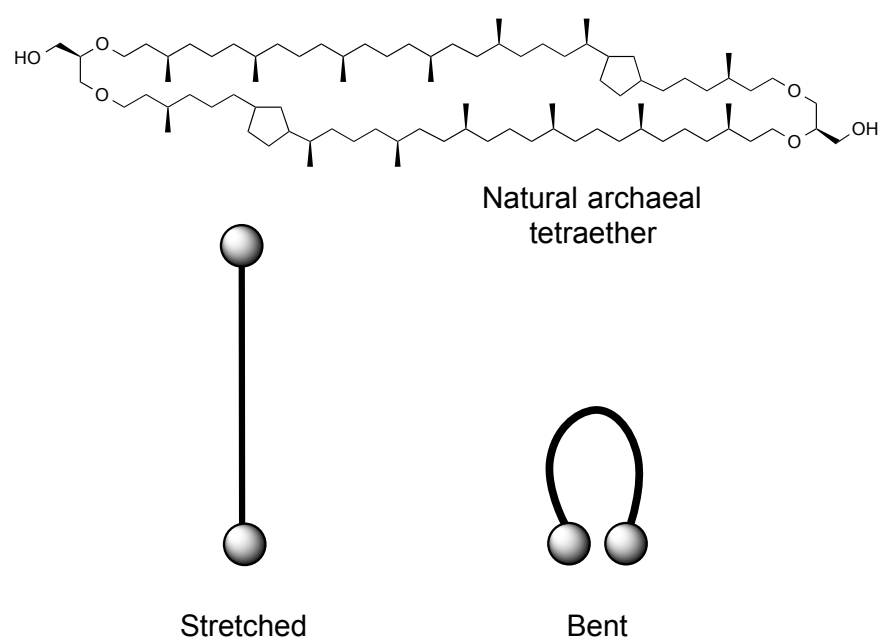

Fig. 1. Example of natural archaeal tetraether, Stretched and bent conformations of bipolar lipid

We designed and synthesized bio-inspired archaeal lipid analogues that kept the main features of natural tetraether lipids. Due to the simplification of the synthetic route, our analogues include 10 stereogenic centers and a unique central cyclopentyl ring. However they can be considered as relatively good models for such a fundamental study on the effect of stereochemical variations. In addition this type of analogue is currently under investigation for the preparation of efficient drug or gene delivery systems for which physicochemical evaluations are useful.[20, 29]

In more details, the hydrophobic domain is based on a 34-carbon atom chain including a central cyclopentyl ring and two glyceryl moieties at both ends (Figure 2). The glyceryl groups are further equipped with two sterereocontrolled phytanyl chains and two lactosyl polar head groups (4 and 5) or simpler hydroxyl functions (3). Our synthetic route[23] permitted to prepare different diastereoisomers that only differ in one stereogenic center at the central cyclopentyl ring (trans $(\mathbf{3}, 4)$ and cis (5)). We described herein a comparative air/water interface study of these tetraethers $(\mathbf{3 , 4 , 5})$ in addition to the diether (monopolar) counterparts (1 and $\mathbf{2})$.
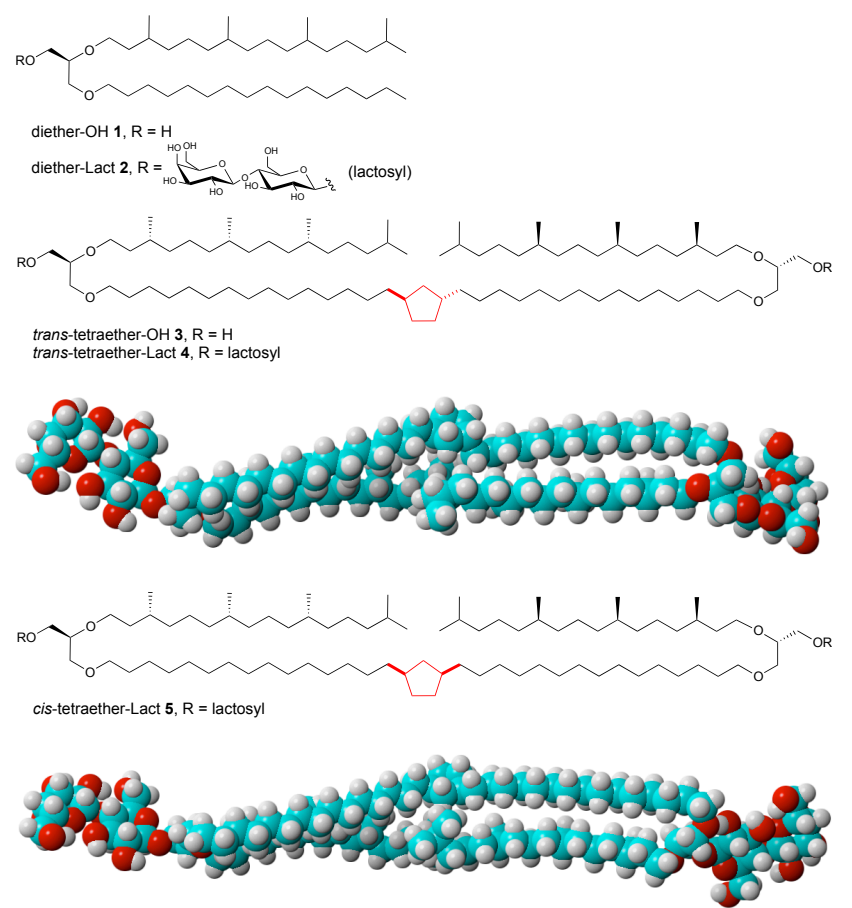

Fig. 2 Structure of synthetic archaeal analogues studied herein and CPK model of tetraether $\mathbf{4}$ and $\mathbf{5}$. 
Tetraethers 4 and 5 have already been evaluated by CryoTEM ( $1 \mathrm{mg} \cdot \mathrm{mL}^{-1}$ in aqueous solution) and by SAXS (50 mg.mL $\mathrm{mL}^{-1}$ in aqueous solution). These previous results already demonstrated clear differences between these two diastereomers. In summary, the trans-isomer $\mathbf{4}$ formed multilamellar vesicles at low concentration in water and surprisingly this lipid was not sensitive to temperature increase (from $20^{\circ} \mathrm{C}$ to $100^{\circ} \mathrm{C}$ ) keeping a $\mathrm{L}_{\alpha}$ phase during a sequential heating of a sample placed in a SAXS capillary holder. The cis-isomer showed mainly unilamellar objects of various types (lamellae, irregular vesicles, ..). When heating this isomer under the same conditions than the trans-isomer, it revealed two phase transitions $\left(\mathrm{L}_{\mathrm{c}} \rightarrow \mathrm{L}_{\mathrm{a}} \rightarrow \mathrm{Q}_{\mathrm{II}}\right)$. Therefore the cis-isomer has a higher conformational flexibility compatible with a $\mathrm{L}_{\mathrm{a}} \rightarrow \mathrm{Q}_{\text {II }}$ phase transition for instance.

In the present study we wanted to evaluate further the behavior of these two isomers with the aim to raise our conclusions to a molecular level and conclude on their preference for a stretched or a bent conformation. Tensiometric and ellipsometric measurements during compression/expansion of Langmuir monolayers in addition to AFM studies of Langmuir-Blodgett samples are known to provide important data about lipid packing organization and orientation at the air/water interface.[3033] Moreover, these techniques are sufficiently sensitive to reveal the slight stereochemical variation that distinguishes the two bipolar lipids $\mathbf{4}$ and $\mathbf{5}$.

\section{Experimental Section}

\section{Synthesis}

General. The preparation of lipids 1, 3-5 have been described previously by our research group.[20, 23] All reactions were carried out under a nitrogen atmosphere with dry, freshly distilled solvents under anhydrous conditions. Tetrahydrofuran (THF) and diethyl ether $\left(\mathrm{Et}_{2} \mathrm{O}\right)$ were dried by passage over a column of activated alumina; dichloromethane $\left(\mathrm{CH}_{2} \mathrm{Cl}_{2}\right)$ was distilled over calcium hydride. All other reagents were used directly from the supplier without further purification unless noted. Analytical thin-layer chromatography (TLC) was performed on $60 \mathrm{~F}_{254}$ silica gel non-activated plates. A solution of $5 \% \mathrm{H}_{2} \mathrm{SO}_{4}$ in EtOH or ultra violet fluorescence was used to develop the plates. Column chromatography was performed on silica gel $60 \mathrm{H}(5-40 \mu \mathrm{m})$. Nuclear magnetic resonance spectra were recorded at $400 \mathrm{MHz}\left({ }^{1} \mathrm{H}\right)$ and $100 \mathrm{MHz}\left({ }^{13} \mathrm{C}\right)$. For $\mathrm{CDCl}_{3}$ and pyridine- $\mathrm{d}^{5}$ solutions, the chemical shifts $(\delta)$ are reported as parts per million (ppm) referenced to the appropriate residual solvent peak. Coupling constants are reported in Hertz $(\mathrm{Hz})$. Data are reported as follows: chemical shift (multiplicity, coupling constants where applicable, number of hydrogen atoms, attribution). Abbreviations are as follows: $s$ (singlet), $d$ (doublet), $t$ (triplet), $q$ (quartet), $d d$ (doublet of doublet), $d t$ (doublet of triplet), $m$ (multiplet), $b s$ (broad singlet). High-resolution mass spectra (Accurate mass) were performed on a MS/MS-TOF mass spectrometer and are reported as $\mathrm{m} / \mathrm{z}$. Accurate masses are reported for the molecular ion $[\mathrm{M}+\mathrm{Na}]^{+},[\mathrm{M}+\mathrm{H}]^{+}$, or $[\mathrm{M}+]$.

Synthesis of diether $\mathbf{2}$. The introduction of a lactosyl group on $\mathbf{1}$, thereby accessing diether $\mathbf{2}$, has been achieved following a procedure described previously[23] and as follow.

Synthesis of diether 2. Diether 1 (200 mg; 1.0 equiv. ; $0.33 \mathrm{mmol}), 2,3,6$-tri- $O$-benzoyl-4- $O$-(2,3,4,6-tetra- $O$-benzoyl- $\beta$-Dgalactopyranosyl)- $\alpha$-D-glucopyranose trichloroacetimidate $(1.22 \mathrm{~g} ; 3.0$ equiv. ; $0.99 \mathrm{mmol})$ were dissolved in $\mathrm{CH}_{2} \mathrm{Cl}_{2}(40$ $\mathrm{mL})$. TMSOTf $\left(5 \%\right.$ in $\mathrm{CH}_{2} \mathrm{Cl}_{2} ; 121 \mu \mathrm{L} ; 0.1$ equiv. ; $\left.0.03 \mathrm{mmol}\right)$ was added. After stirring $2 \mathrm{~h}$ at room temperature, the reaction was quenched with sat. aq. $\mathrm{NaHCO}_{3}$, the precipitate was filtered out and washed with $\mathrm{CH}_{2} \mathrm{Cl}_{2}$. The filtrate was concentrated under reduced pressure and purified by silica gel column chromatography (Cyclohexane/AcOEt 80:20) to give glycosylated diether protected-2 $(356 \mathrm{mg} ; 0.21 \mathrm{mmol})$ as whitish solid. Yield $=64 \% ; \mathrm{R}_{f}=0.3$ (Cyclohexane/AcOEt $80: 20) ;[\alpha]_{\mathrm{D}}{ }^{20}=+30\left(\mathrm{c} 1.2, \mathrm{CH}_{3} \mathrm{Cl}\right) ;{ }^{1} \mathrm{H}$ NMR $\left(\mathrm{CDCl}_{3}, 400 \mathrm{MHz}\right) \delta(\mathrm{ppm}): 0.67-1.72(70 \mathrm{H}, \mathrm{m}), 3.22(2 \mathrm{H}, \mathrm{dt}, J=6.7,1.9$ $\mathrm{Hz}), 3.29(2 \mathrm{H}, \mathrm{dt}, J=5.0 \mathrm{~Hz}), 3.34-3.40(2 \mathrm{H}, \mathrm{m}), 3.44-3.49(1 \mathrm{H}, \mathrm{m}), 3.49-3.54(2 \mathrm{H}, \mathrm{m}), 3.69(2 \mathrm{H}, 2 \mathrm{dd}, J=11.4,6.6 \mathrm{~Hz})$, 3.79-3.83 (1H, m), 3.84-3.86 (1H, m), $3.90(1 \mathrm{H}, \mathrm{m}), 4.25(1 \mathrm{H}, \mathrm{t}, J=9.5 \mathrm{~Hz}), 4.48(1 \mathrm{H}, \mathrm{dd}, J=12.2,4.1 \mathrm{~Hz}), 4.58(1 \mathrm{H}, \mathrm{dd}, J$ $=12.1,1.4 \mathrm{~Hz}), 4.77(1 \mathrm{H}, \mathrm{d}, J=7.9 \mathrm{~Hz}), 4.87(1 \mathrm{H}, \mathrm{d}, J=7.9 \mathrm{~Hz}), 5.35(1 \mathrm{H}, \mathrm{dd}, J=10.3,3.4 \mathrm{~Hz}), 5.47(1 \mathrm{H}, \mathrm{dd}, J=9.9,7.9$ $\mathrm{Hz}), 5.59-5.73(2 \mathrm{H}, \mathrm{m}), 5.79(1 \mathrm{H}, \mathrm{t}, J=8.2 \mathrm{~Hz}), 7.14(2 \mathrm{H}, \mathrm{t}, J=7.8 \mathrm{~Hz}), 7.21(2 \mathrm{H}, \mathrm{t}, J=7.8 \mathrm{~Hz}), 7.28-7.35(5 \mathrm{H}, \mathrm{m}), 7.37-$ $7.43(5 \mathrm{H}, \mathrm{m}), 7.46-7.51(5 \mathrm{H}, \mathrm{m}), 7.54-7.63(3 \mathrm{H}, \mathrm{m}), 7.72(2 \mathrm{H}, \mathrm{dd}, J=8.4,1.4 \mathrm{~Hz}), 7.89-8.02(11 \mathrm{H}, \mathrm{m}) ;{ }^{13} \mathrm{C} \mathrm{NMR}\left(\mathrm{CDCl}_{3}\right.$, $100 \mathrm{MHz}) \delta(\mathrm{ppm}): 14.1,19.67,19.74,22.62,22.68,22.71,24.3,24.5,24.8,26.0,26.9,28.0,29.4,29.46,29.52,29.59$, $29.64,29.65,29.67,29.70,30.2,31.9,32.78,32.80,36.9,37.0,37.3,37.39,37.41,37.43,37.47,37.50,37.53,39.4,43.5$, $61.0,62.4,67.5,69.1,69.9,70.39,70.43,70.63,70.67,71.4,71.6,71.7,71.8,72.91,72.94,76.0,77.6,77.7,101.0,101.4$, $128.20,128.23,128.3,128.53,128.56,128.62,128.67,128.9,129.35,129.42,129.5,129.60,129.64,129.65,129.74,129.76$, $129.79,130.0,133.1,133.2,133.3,133.36,133.38,135.5,164.8,165.1,165.2,165.37,165.39,165.6,165.8$. A solution of sodium methanolate in $\mathrm{MeOH}\left(0.1 \mathrm{~mol}^{-1} \mathrm{~L} ; 10.2 \mathrm{~mL}\right)$ was added to a solution of glycosylated diether protected-2 $(335 \mathrm{mg}$; 1.0 equiv. ; $0.15 \mathrm{mmol})$ in $\mathrm{MeOH}(16 \mathrm{~mL})$ and $\mathrm{CH}_{2} \mathrm{Cl}_{2}(13 \mathrm{~mL})$. The resulting mixture was stirred at room temperature for 14 $\mathrm{h}$ and neutralized by adding Amberlite IR 120 resin. After filtration and concentration, the residue was purified by silica gel column chromatography $\left(\mathrm{CHCl}_{3} / \mathrm{MeOH} 90: 10\right)$ to yield final diether $2(166 \mathrm{mg} ; 0.13 \mathrm{mmol})$ as white solid. Yield $=89 \%$; $\mathrm{R}_{f}=0.08\left(\mathrm{CHCl}_{3} / \mathrm{MeOH} 90: 10\right) ;[\alpha]_{\mathrm{D}}{ }^{20}=-2.6\left(\mathrm{c} 1.1, \mathrm{CHCl}_{3} / \mathrm{MeOH} 80: 20\right) ;{ }^{1} \mathrm{H}$ NMR (pyridine-d5, $\left.400 \mathrm{MHz}\right) \delta(\mathrm{ppm})$ : $0.91(18 \mathrm{H}, \mathrm{m}), 1.11-1.80(52 \mathrm{H}, \mathrm{m}), 3.48(2 \mathrm{H}, \mathrm{dq}, J=6.9,2.6 \mathrm{~Hz}), 3.69-3.73(1 \mathrm{H}, \mathrm{m}), 3.75-3.86(3 \mathrm{H}, \mathrm{m}), 3.87-3.91(1 \mathrm{H}, \mathrm{m})$, 3.95-4.02 (2H, m), $4.06(1 \mathrm{H}, \mathrm{t}, J=8.1 \mathrm{~Hz}), 4.13-4.18(2 \mathrm{H}, \mathrm{m}), 4.26-4.34(3 \mathrm{H}, \mathrm{m}), 4.41(1 \mathrm{H}, \mathrm{dd}, J=10.9,5.4 \mathrm{~Hz}), 4.45-4.57$ $(5 \mathrm{H}, \mathrm{m}), 4.90(1 \mathrm{H}, \mathrm{dd}, J=7.8,1.9 \mathrm{~Hz}), 5.11(1 \mathrm{H}, \mathrm{d}, J=7.8 \mathrm{~Hz}) ;{ }^{13} \mathrm{C}$ NMR (pyridine-d5, $\left.100 \mathrm{MHz}\right) \delta(\mathrm{ppm}): 14.7,20.18$, $20.24,20.30,23.1,23.2,23.3,25.2,25.5,26.9,28.6,30.0,30.2,30.3,30.4,30.6,32.5,33.43,33.46,37.9,38.01,38.05$, $38.10,38.15,38.18,38.3,39.9,62.4,62.6,69.2,69.3,70.4,70.5,72.8,75.0,75.6,76.9,77.1,77.6,78.9,79.0,82.6,105.2$, 
106.2. ; Accurate mass calcd for $\mathrm{C}_{51} \mathrm{H}_{100} \mathrm{O}_{13} \mathrm{Na}(\mathrm{M}+\mathrm{Na})^{+} 943.70541$ found 943.7047.

\section{Tensiometry/Ellipsometry}

Experiments were performed with a computer-controlled and user-programmable Langmuir Teflon-coated trough (type 601BAM, equipped with two movable barriers of total surface $716 \mathrm{~cm}^{2}$, Nima Technology Ltd., England). Before starting experiments, the trough was cleaned successively with ultrapure water (Nanopure-UV), ethanol and finally warm ultrapure water. The trough was filled with water and isotherms were recorded to verify the absence of impurity. The temperature was $20^{\circ} \mathrm{C}$. Lipids were dissolved in a $2: 1$ chloroform $/$ methanol solution $(\mathrm{v} / \mathrm{v})$ at $0.3 \mathrm{mM}$. Lipids were spread over the clean air/water interface between movable barriers using a high precision Hamilton microsyringe at a pressure of $0 \mathrm{mN} \mathrm{m}^{-1}$. After ten minutes to allow evaporation of the solvent, films were compressed by moving barriers at a rate of $18.6 \mathrm{~cm}^{2} / \mathrm{min}^{-1}$ from 600 to $38 \mathrm{~cm}^{2}$. The film was then compressed continuously on the collapse until the minimal trough area. After a waiting time of seven minutes, decompression was performed at the previous compression rate. Simultaneously to the surface pressure, the ellipsometric angle $\Delta$ was recorded and both are presented versus the mean molecular area. The surface pressure was measured following a Wilhelmy-plate method using a filter paper connected to a microelectronic feedback system for surface pressure measurements. Values of surface pressure $(\pi)$ were stable and recorded every $4 \mathrm{~s}$ with a precision of \pm 0.2 $\mathrm{mN} \mathrm{m}^{-1}$. Ellipsometry measurements were carried out with an home-made automated ellipsometer in a "null ellipsometer" configuration.[34, 35] He-Ne laser beam $(\lambda=632.8 \mathrm{~nm}$, Melles Griot) is polarised with a Glan-Thompson polarizer and reflected on the surface of the trough (incidence angle of $52.12^{\circ}$ ). After reflection on the water surface, the laser light passed through a $\lambda / 4$ retardation plate, a Glan-Thompson analyser and a photomultiplier. The analyser angle, multiplied by two, yielded the value of the ellipsometric angle $(\Delta)$ i.e., the phase difference between parallel and perpendicular polarisation of the reflected light. The laser beam probed a surface of $1 \mathrm{~mm}^{2}$ and a depth in the order of $1 \mu \mathrm{m}$. Values of $\Delta$ were recorded every $4 \mathrm{~s}$ with a precision of $\pm 0.5^{\circ}$.

Isotherms ( $\pi$ or $\Delta$ as function to molecular area (A)) presented in the manuscript are representative of triplicated experiments. The standard deviation on the values of the mean molecular areas was found to be $\pm 2 \AA^{2}$ per molecule. All experiments were performed at room temperature between 19 and $21^{\circ} \mathrm{C}$. The sub-phase is deionized milli-Q water at $\mathrm{pH}$ of 6.7.

In order to compare the behavior of film during the compression and the decompression, the surface elasticity defined by Gibbs, from a priori considerations was calculated using:

$$
\mathrm{E}=-\mathrm{A}(\delta \pi / \delta \mathrm{A})_{\mathrm{T}}[36,37]
$$

\section{Atomic Force Microscopy}

For imaging, the film was transferred to a freshly-cleaved mica support by Langmuir-Blodgett method. To avoid loss of matter, the transfer was done at constant pressure and at a very low speed $\left(0.5 \mathrm{~mm} \mathrm{~min}^{-1}\right)$. The mica plate was then observed with an atomic force microscope (Molecular Imaging, Picoplus, Scientec, France). Imaging was carried out using the intermittent contact mode in air with standard silicon cantilevers (ACT, Nanoprobes, Scientec, France) and at a scan rate of 1 Hz. The force was adjusted to a minimum during the scan. To verify the integrity of the sample after the different scan and zoom, the same zone was imaged at the end of the analysis. The scanner size was $100 \mu \mathrm{m} x 100 \mu \mathrm{m}$. Presented images are representative of duplicated experiments.

\section{Results}

Tensiometry/Ellipsometry. We started our investigation by studying the behavior of diether-OH 1 and trans-tetraether-OH 3 at the air-water interface. Tensiometric and ellipsometric data were collected during compression and expansion of the corresponding Langmuir films. The surface pressure provides information on the lateral interaction between lipids upon compression. The ellipsometric angle $(\Delta)$ is proportional to the reflexion index and therefore to the thickness of the lipid film. The reflexion index can be considered constant during compression/decompression processes permitting to consider $\Delta$ as a function of the film thickness.[38, 39] Surface pressure / area per molecule $(\pi-\mathrm{A})$ and ellipsometric angle / surface pressure $(\Delta-\pi)$ isotherms are shown on figure 3. The behavior of diether-OH 1 which has already been described is similar to other bicatenar lipids.[22, 40] In contrast the trans-tetraether-OH 3 conduced to approximately twice lift-off and limiting area values (Fig. 3, Table 1). Consequently, the bipolar lipid 3 adopts a bent-shape conformation at the air/water interface keeping the two $\mathrm{OH}$ groups into the subphase. However, compared to our previous study [22] the absence of the oxygen atoms within the hydrophobic core dramatically reduced the lift-off point value meaning that the tetraether lipid adopts a less opened-bent conformation at this stage of compression. In fact the values obtained here are comparable to those obtained with natural archaeal tetraether lipids.[41, 42] Surface pressures at collapse demonstrate that the monolayer composed of diether-OH $\mathbf{1}$ is more stable than that of tetraether-OH 3. Indeed this observation can be due to less efficient lateral molecular interactions in the case of the tetraether-OH 3 , the presence of the cyclopentane decreasing the cohesive forces between hydrophobic tails.[37] The ellipsometric data describe an initial increasing $\Delta$ at $0 \mathrm{mN} \cdot \mathrm{m}^{-1}$ which is related to the presence of molecules forming a liquid expanded lipid film at the interface. Between 0 to collapse pressure the increasing value is related to the lateral compression of the liquid expanded (LE) phase. The final sharp increase in $\Delta$ at collapse pressure for both diether-OH 1 and tetraether-OH 3, reflects a dramatic increase of the film thickness and implies the formation of a three dimensional phase. Decompression of the corresponding three dimensional structures led to a slight hysteresis in the case of tetraether-OH 
3. This loss of material would be related to the presence of 3D structures even after a full opening of the barrier. As the ellipsometric angle corresponds to an average value of a small area of the Langmuir trough illuminated by the laser beam, this hysteresis is difficult to observe on the $\Delta$ - $\pi$ isotherm.
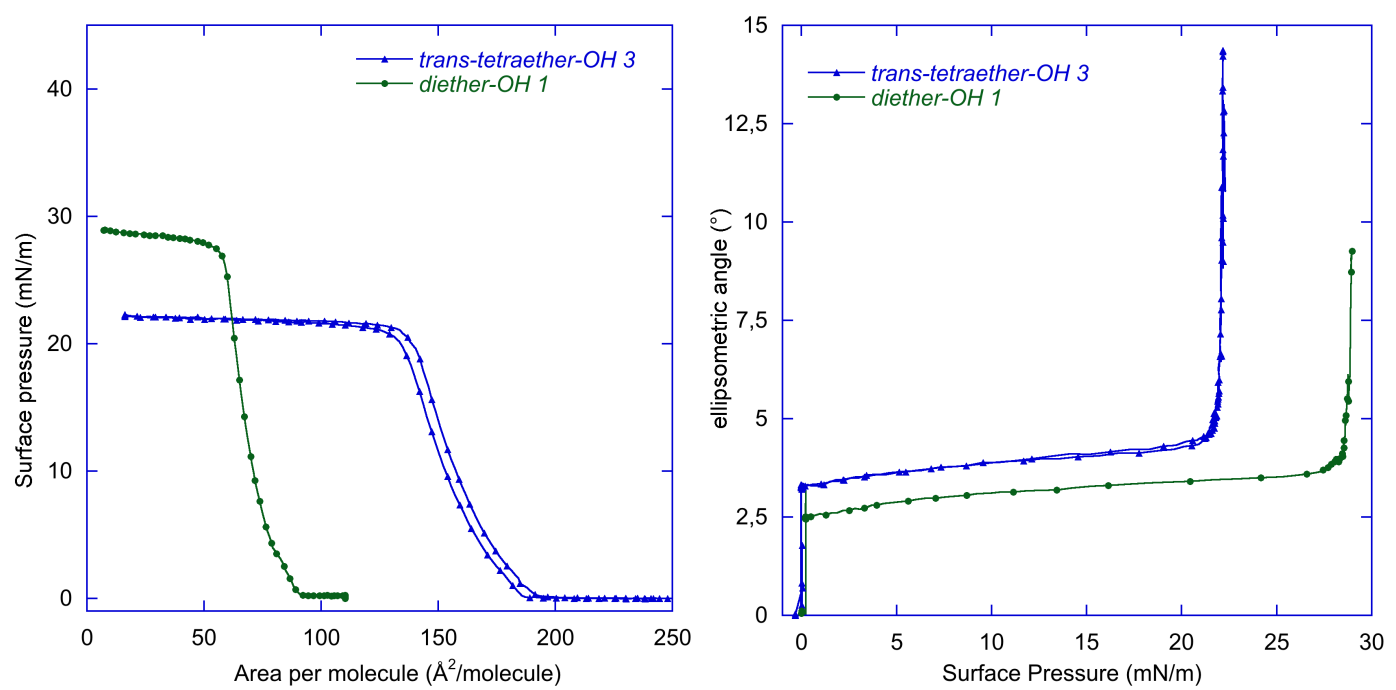

Fig. 3 Compression/expansion isotherms of trans-tetraether-OH 3 and diether-OH 1 (30\% of points shown).

The isotherms obtained with diether-Lact 2 and trans-tetraether-Lact $\mathbf{4}$ show comparable differences and characteristics (Figure 4). The lift-off point of the trans-tetraether-Lact $\mathbf{4}$ is about the double of the value for diether-Lact $\mathbf{2}$ which is again consistent with a bent conformation of the tetraether core. Compression after collapse led to the formation of three dimensional structures as shown by the increase of $\Delta$ at collapse pressure on the $\Delta-\pi$ isotherms (Figure 4). The higher pressures obtained at the collapse demonstrated a higher stabilization of monomolecular film formed by lipids equipped with lactosyl polar head groups instead of simple hydroxyl functions. Surprisingly, the expansion step led to a high hysteresis phenomenon for both diether (2) and tetraether (4) lipids, thereby demonstrating the difficult destabilization of the three dimensional structures formed during collapse. The remaining of the three dimensional domains during the expansion is also confirmed by the $\Delta-\pi$ isotherm (Figure 4). The diether-Lact 2 is characterized by a decreasing value of $\Delta$ upon decompression that implies the disappearance of the three dimensional structures. The hysteresis is however no more observed on the $\Delta-\pi$ isotherm below $35 \mathrm{mN} . \mathrm{m}^{-1}$. In comparison, the tetraether-Lact 4 has a different thickness profile. Upon decompression $\Delta$ varies from 10 to $20^{\circ}$ which is consistent with the presence of more or less 3D structures. At about 10 $\mathrm{mN} \cdot \mathrm{m}^{-1}, \Delta$ decreases regularly from 11 to $6^{\circ}$ demonstrating a more homogeneous film thickness evolution. This part of the data is associated with the plateau at $10 \mathrm{mN} \cdot \mathrm{m}^{-1}$ found in the $\pi$-A isotherm. Therefore, on both $\pi-\mathrm{A}$ and $\Delta-\pi$ isotherms, the hysteresis is larger in the case of the trans-tetraether-Lact 4 that required reaching $10 \mathrm{mN} \cdot \mathrm{m}^{-1}$ to recover the original monolayer film. At this pressure the isotherm appeared as a slightly decreasing plateau corresponding to the recovering of the original monolayer lipid film. Lactosyl and disaccharides in general are able to create strong hydrogen bond network between two residues leading to a clear stabilization of monomolecular films.[43, 44] The formation of a hydrogen bond network in the case trans-tetraether-Lact $\mathbf{4}$ is responsible for a lower limiting area and a higher collapse pressure value in comparison with trans-tetraether-OH 3 (Table 1). The combination of this lactosyl head group with a tetraether hydrophobic core dramatically amplified the stabilization of the so formed three dimensional structures. These 3D-domains are stable enough to be maintained after the full decompression that leads to the loss of material observed at the end of the expansion process. 

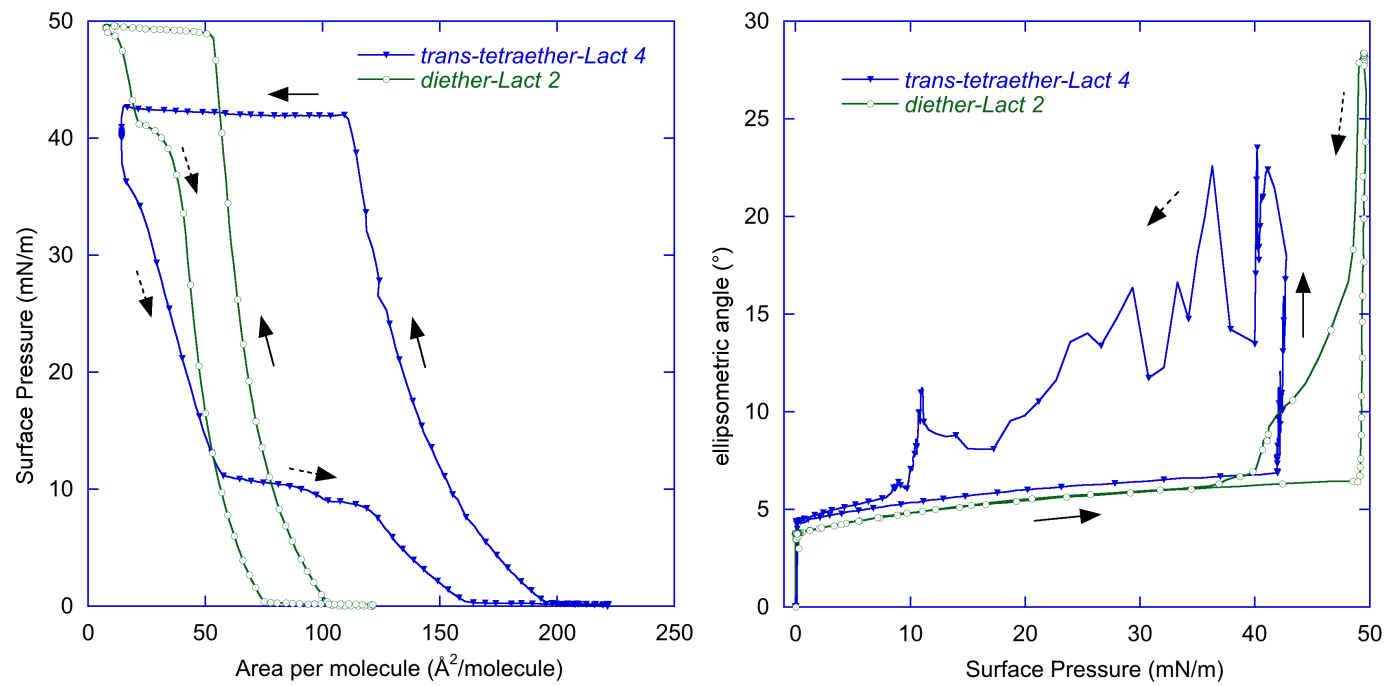

Fig. 4 Compression/expansion isotherms of trans-tetraether-Lact 4 and diether-Lact 2 (30\% of points shown, arrows correspond to compression (full line) and expansion (dotted line)).

Tetraethers $\mathbf{4}$ and $\mathbf{5}$ differ only by the relative stereochemistry of the two stereogenic centers of the central cyclopentane ring. We carried out the same investigations described before. The comparison of the results obtained from these two diastereoisomers gives insights into the impact of this slight stereochemical variation. Globally, trans (4) and cis (5) isomers revealed very similar shape of compression/expansion isotherms (Figure 5). This observation means that whatever the stereochemistry of the cyclopentane ring, these tetraether glycolipids adopt a bent conformation as shown by the high area per molecule values at lift points and limiting areas (Figure 5, Table 1). The $\Delta-\pi$ isotherms show similar shapes during compression and formation of the 3D structures. Furthermore we studied the relaxation of the films at constant area on the collapse by keeping the barriers immobile for seven minutes (Figure 5). During that time no disruption of the films appears, only a slight pressure relaxation of $\approx 2 \mathrm{mN} \cdot \mathrm{m}^{-1}$ occurs. Interestingly, the compression/expansion of monomolecular films composed of a 1:1 mixture of both isomers 4/5 (obtained by synthesis)[23] gave similar isotherms. However, beside the similar shape of the compression/expansion isotherms, several slight differences revealed some characteristics of each isomer.

The compression of the LE phase led to identical $\pi$-A isotherms whatever the isomer until $26 \mathrm{mN} . \mathrm{m}^{-1}$. From this surface pressure, the cis isomer follows compression at a same rate while the slope of the isotherm obtained for the trans isomer increases significantly. Using equation 1, the surface elasticity is calculated between surface pressures of 27 and 39 mN.m ${ }^{-1}$. The values range from 84.8 to $93.5 \mathrm{mN} . \mathrm{m}^{-1}$ for the $\mathrm{cis}$ isomer and 123 to $136 \mathrm{mN} . \mathrm{m}^{-1}$ for the trans isomer. Thus, the cis isomer shows a higher compressibility than the trans one, which means that within a bent-conformation, the two sugar head groups are closer in the case of the cis-isomer. This packing difference suggests a different orientation of the sugar head groups and consequently the formation of different type of hydrogen bonding network between the sugar residues (intramolecular or intermolecular for instance).

Using the decompression curve, the layer elasticity was calculated between surface pressure of 23 and $15 \mathrm{mN}^{-1} \mathrm{~m}^{-1}$ (just before the decompression plateau). The trans-isomer elasticity values were comprised between 25 and $33 \mathrm{mN} . \mathrm{m}^{-1}$ against $18-24$ $\mathrm{mN} . \mathrm{m}^{-1}$ for the cis-isomer. This difference confirms that the lateral structure formed by the trans-isomer is more rigid or more resistant to stress than that formed by the cis-isomer.

Another slight difference can be found in the shape of the plateau at around $10 \mathrm{mN} . \mathrm{m}^{-1}$ during decompression. Indeed the cis isomer 5 conduced to a perfectly horizontal plateau instead of the decreasing plateau exhibited for the trans isomer 4 . A horizontal plateau clearly corresponds to a single transition while a decreasing plateau implies at least two phenomena. Therefore the three dimensional domains disorganized in different manner which also means that the two isomers do not adopt the same conformation within the multilayers. Furthermore, at the end of the plateau during decompression, both isomers recover the initial ellipsometric angle values of the monolayers. 

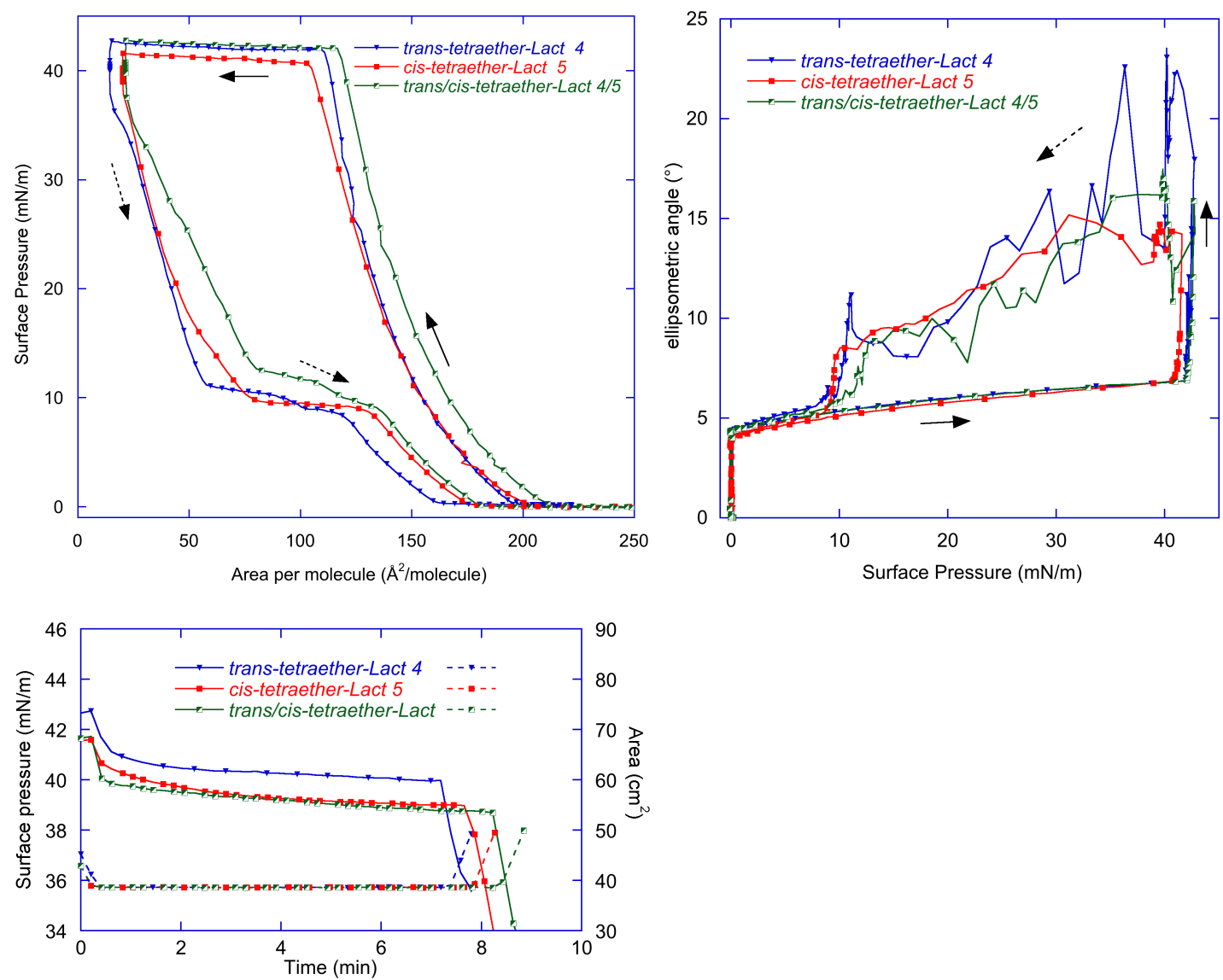

Fig. 5 Compression/decompression isotherms of trans-tetraether-Lact 4, cis-tetraether-Lact $\mathbf{5}$ and trans/cis-tetraether $\mathbf{4} / \mathbf{5}$ and Relaxation of about $7 \mathrm{~min}$ at constant area at collapse (30\% of points shown, arrows correspond to compression (plain line) and expansion (dotted line)).

Atomic Force Microscopy. To complete the above thermodynamic data, we carried out Langmuir-Blodgett sampling at 20 $\mathrm{mN} \cdot \mathrm{m}^{-1}$ (at constant pressure) on mica plates during both the compression and expansion stages. Upon compression, we expected to confirm the absence of phase transition and at the decompression we expected to observe the three dimensional domain and its disassembling permitting to gather information on their stability and on their mode of formation. The AFM topography of the film transferred during the compression step gave flat and homogeneous surfaces (see ESI) for both stereoisomers 4,5. This confirms that the two tetraethers are in fluid state and adopt a homogeneous conformation within the lipid film at that stage of compression. The AFM topographies obtained from samples prepared during expansion $\left(20 \mathrm{mN} . \mathrm{m}^{-}\right.$ ${ }^{1}$ ) brought crucial information on the behavior of such tetraether lipids during the disassembly of structures formed during collapse. These AFM topographies are shown on Figure 6. Interestingly, they revealed the presence of multilayers that are partly disassembled at this surface pressure $\left(20 \mathrm{mN} \cdot \mathrm{m}^{-1}\right)$. It points out also the particular stability of the multilayers at such a low surface pressure. The AFM topography recorded from the cis-isomer $\mathbf{5}$ is characterized by the presence of multilayer domains with an apparent height of $7.5 \mathrm{~nm}$. The surface of the layers is rather flat whatever the level considered (mono or multilayer) and the partial disorganization observed at $20 \mathrm{mN} \cdot \mathrm{m}^{-1}$ is characterized by round shape dark domains (Figure 6a) embedded in a discontinuous multilayer. Some round flat patches of higher height strewed the surface. Meanwhile the topographies obtained from the trans-isomer 4 showed multilayers with a significantly smaller apparent height of 5-6 nm. Rift-type dark domains are observed instead of the round shape domains and a clear roughness appeared on the surface of the multilayers responsible for the height variation between 5 and $6 \mathrm{~nm}$ (Figure 6b, Line B, and zoom). Both kinds of dark domains were revealed on the topography obtained from the 1:1 mixture of isomers $\mathbf{4 / 5}$ (Figure $6 \mathrm{c}$ ). Moreover the height difference $(1.5 \mathrm{~nm}$ ) is obvious on this topography (Figure 6c), thereby demonstrating coexistence of more or less thicker domains within the multilayers. 

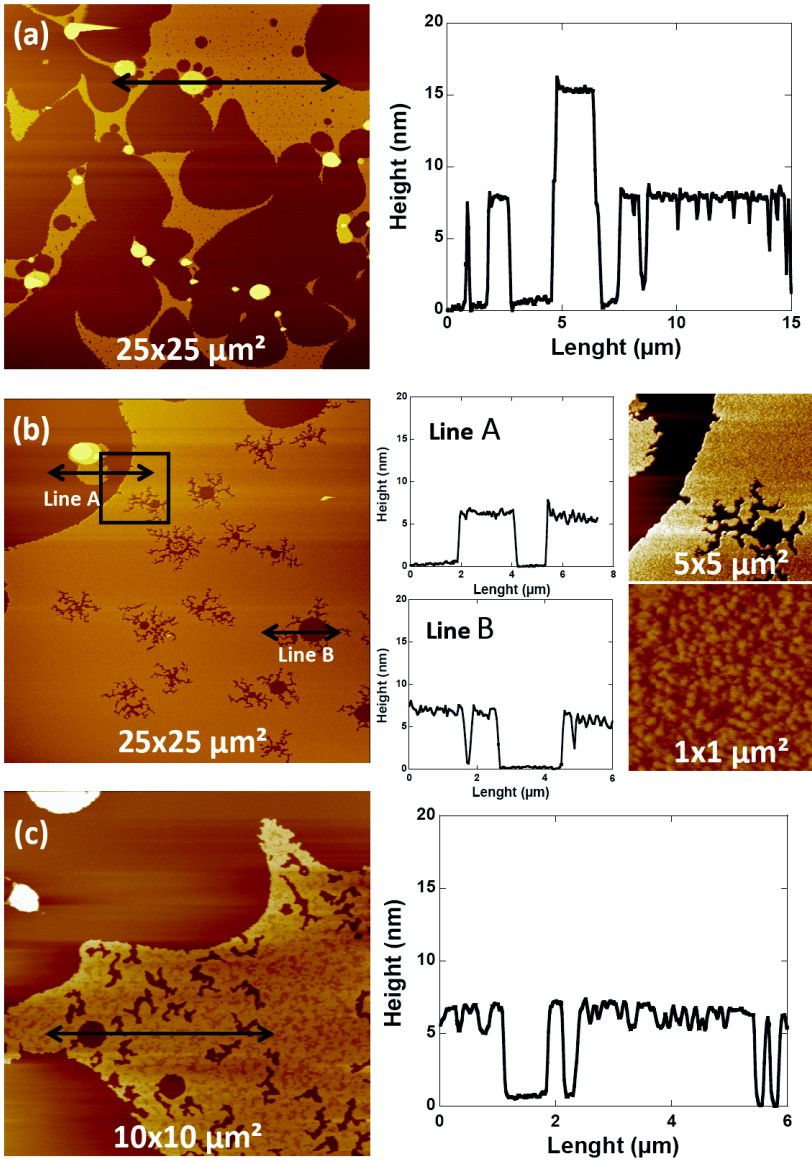

Fig. 6 AFM topographies of Langmuir-Blodgett sampling at $20 \mathrm{mN} \cdot \mathrm{m}^{-1}$ (expansion) (a) cis-tetraether-Lact 5, (b) trans-tetraether-Lact 4, (c) trans/cis-tetraether-Lact $\mathbf{4} / \mathbf{5}$.

\section{Discussion}

On the basis of the results described above, the main data gathered in table 1 and the schematic representation in Figures 7-9 permit to summarize the behavior of tetraether glycolipids $\mathbf{4}$ and $\mathbf{5}$ at the air/water interface.

Table 1 Main values recorded from the surface pressure/area per molecule isotherms and AFM studies (representative of triplicates).

\begin{tabular}{ccccc}
\hline Compounds & $\begin{array}{c}\text { Lift-off } \\
\text { point }\left(\AA^{2}\right)\end{array}$ & $\begin{array}{c}\text { Limit. area } \\
\left(\AA^{2} \pm 2 \AA^{2}\right)\end{array}$ & $\begin{array}{c}\pi \text { collapse Multilayer } \\
\left(\mathrm{mN} \mathrm{m}^{-1}\right)\end{array}$ & Height $(\mathrm{nm})$ \\
\hline Diether-OH 1 & 92 & 58 & 27.7 & - \\
Diether-Lact 2 & 103 & 54 & 49.3 & - \\
trans-Tetraether-OH 3 & 179 & 138 & 21.3 & - \\
trans-Tetraether-Lact 4 & 196 & 111 & 41.8 & $5-6$ \\
cis-Tetraether-Lact 5 & 203 & 104 & 40.6 & 7.5 \\
Tetraether-Lact 4/5 & 210 & 117 & 42.0 & $7 \pm 1.5$ \\
& & & & \\
\hline
\end{tabular}

First of all, comparison of molecules $\mathbf{1 , 2}$ and $\mathbf{3 , 4}$ confirms that the presence of lactosylated head group stabilized the monolayer at the interface as shown by the dramatic increase of the collapse pressure for these compounds. In addition the limiting areas of lactosyslated lipids are lower even if this polar head group is much bigger than the hydroxyl function. Establishment of a hydrogen bonding network would explain the attraction between the head group and the film stability.

The pressure/area isotherms of tetraether lipids 4,5 are shifted to area values representing twice of those of diether counterparts. This comparison demonstrates that the bipolar lipids adopt an opened-bent conformation lying on the water surface at the beginning of the compression. This more or less flat conformation evolves to a fully bent conformation between the lift-off point and the limiting area (Figure 7). Similar conclusions using different techniques have been drawn from the study of Jeworrek et al.[45] and Bakowsky et al.[41]. Interestingly, both diastereomers $\mathbf{4}$ and $\mathbf{5}$ adopt this bent conformation the main differences at this stage of compression are a higher compressibility of the cis-isomer $\mathbf{5}$ at a high surface pressure $\left(>25 \mathrm{mN} \cdot \mathrm{m}^{-1}\right)$. Indeed the cis-cyclopentyl ring is able to adopt a conformation under a constraining pressure that places the two substituents (i.e., the two alkyl chains) close one to another (Figure 7). It reduces the distance between 
head groups of a same molecule facilitating intramolecular hydrogen bonding establishment and leading to a lower limiting area per molecule. The trans-cyclopentyl ring has almost a unique conformation allowing a bent shape of the lipid whatever the stage of compression (Figure 7). This conformation brings the two alkyl chains to a higher distance one to another leading to a potential change in the head group orientation and finally to a larger limiting area per molecule.

These observations mean that both isomers involved different preferences in the establishment of the hydrogen bonding network between the sugar moieties depending on the global conformation of the lipid and directly related to the cis or trans configuration of the cyclopentyl ring. This in mind, the main stabilizing factor involved in the organization of the cis-isomer 5 would be intramolecular interactions while intermolecular interactions would take place for the trans-isomer 4 (between two sugar moieties).

Both isomers undergo the formation of multilayers during a further compression after the limiting area. The differences found in the isotherms during the expansion step reveal a different behavior of the lipids during the collapse. Indeed, the collapse mechanism can significantly disrupt the organization of lipid films.[46, 47] The process of collapse and the transition of a monolayer to a three-dimensional phase are not yet well understood and depend on the studied molecules.[48] Formation of multilayers beyond the air/liquid interface was reported in previous studies with phospholipids such as DMPC (dimerystoylphosphatidylcholine) and DOPS (dioleoylphosphatidylserine)[49] or mixture of DPPC/cholesterol[46]. In these studies the interfacial films were observed using a Brewster angle microscope. The images showed round shape domains corresponding to multilayer formation. In contrast, bundles diving in the subphase were observed using the same technique with DOPC (dioleoylphosphatidylcholine) and DOPG (dioleoylphosphatidylglycerol)[49] or 2-OH TCA (2hydroxy tetracosanoïc acid)[50, 51]. In these cases, images do not show domains or well-defined structures. Our AFM images show regular organization with well identified steps corresponding to the height of the different multilayers, thus we are confident that the multilayers described here are formed on the top of the monolayer and not dive in the solution as describe in figure 8 and 9.

Careful analysis of the data collected during expansion steps permits to identify the conformation of the tetraether lipids within mono and multilayers. In more details the cis-isomer (5) shows a tendency to keep several levels of multilayer during the decompression. The height between each step, which was measured by AFM, reaches $7.5 \mathrm{~nm}$ that corresponds to a hydrated bilayer composed of two U-shaped lipids presenting the hydrophobic part outside (Figure 8). During the decompression, the lipids, constituting the monolayer, open inducing the pressure dropping. A further expansion of the film gives a reorganization of the multilayer statistically to the lower level until the formation of the original monolayer (plateau at $10 \mathrm{mN} \cdot \mathrm{m}^{-1}$ ). It is noteworthy that a part of the lipids are kept within the multilayer after the plateau as a gap appears between the end of the decompression and the beginning of the compression.

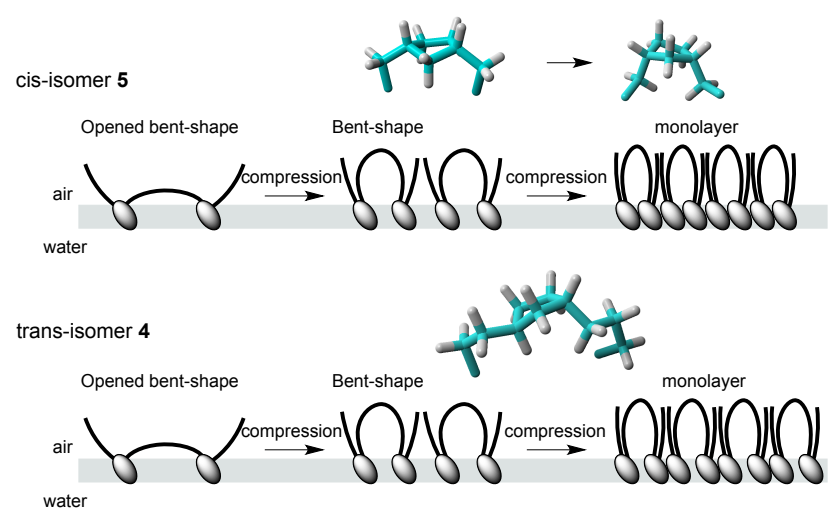

Fig. 7 Representation of the tetraether lipid $\mathbf{4}$ and $\mathbf{5}$ films during compression.

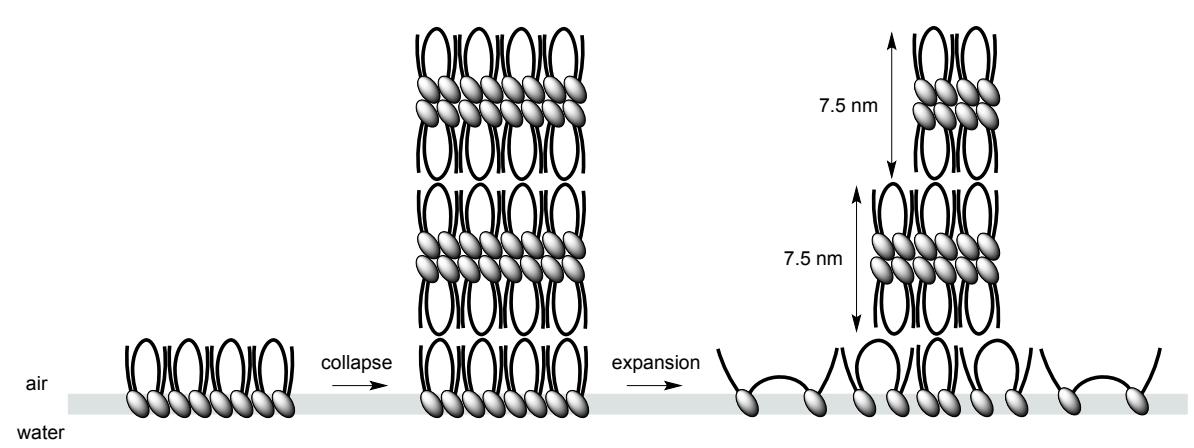

Fig. 8 Representation of the cis-tetraether lipid 5 films during collapse and expansion.

The trans isomer (4) is characterized by similar $\pi$-A and $\Delta-\pi$ isotherms from which several significant differences arise. 
Indeed the AFM of the sample transferred at $20 \mathrm{mN} \cdot \mathrm{m}^{-1}$ revealed a tendency of this lipid to preferentially retain only one step corresponding to a bilayer (or trilayer if including the monolayer of the background) instead of several levels of multilayer. Moreover this bilayer has a shorter height of 5-6 nm compared to the $7.5 \mathrm{~nm}$ found for the cis-isomer whereas the monolayer have the same thickness for both isomers (see ellipsometric data on figure 5). In addition, we observed a clear roughness of the surface of the bilayer $( \pm 1 \mathrm{~nm})$. Again these differences find their origin in the trans configuration of the cyclopentyl ring that constrains the lipid when adopting a bent conformation. The height thinning and the roughness are hard to be explained by suggesting tilted lipids or difference in hydration. In fact the cis isomer $\mathbf{5}$ demonstrated already a higher hydration in aqueous solution[23] but it cannot explain both the 5-6 nm and the roughness obtained for the trans-isomer 4. However, the collapse disruption provides the opportunity to release the constrained bent conformation leading to a slight spacing of the two sugar head groups. It then conduces to an interdigitation of the sugar head from one layer to another reducing the height of the layers by approximately $1 \mathrm{~nm}$ (length of a lactosyl residue) (Figure 9). However, the sole interdigitation cannot explain; 1) the appearance of the roughness and 2) the particular predominance of the trilayer compared to the other layers. We assume that the lipid 4 flips one polar head group on collapse leading to a stretched conformation. The presence of this conformation in mixture with U-shaped conformation impacts the bilayer in the two following ways. First it stabilizes the trilayer, which explains the predominance of this layer for the trans-isomer on the AFM studies. Secondly, considering a mixture with U-shaped conformation, it introduces different heights of layer which justifies the roughness of the trilayer surface (Figure 9). Furthermore, the layer elasticity of the trans-isomer (4) calculated between 23 and $15 \mathrm{mN} . \mathrm{m}^{-1}$ just before the decompression plateau, was higher than for the cis-isomer (5). These higher values confirm that trans-isomer packing is more rigid or resistant to stress than the structuration of the $c i s$-isomer.

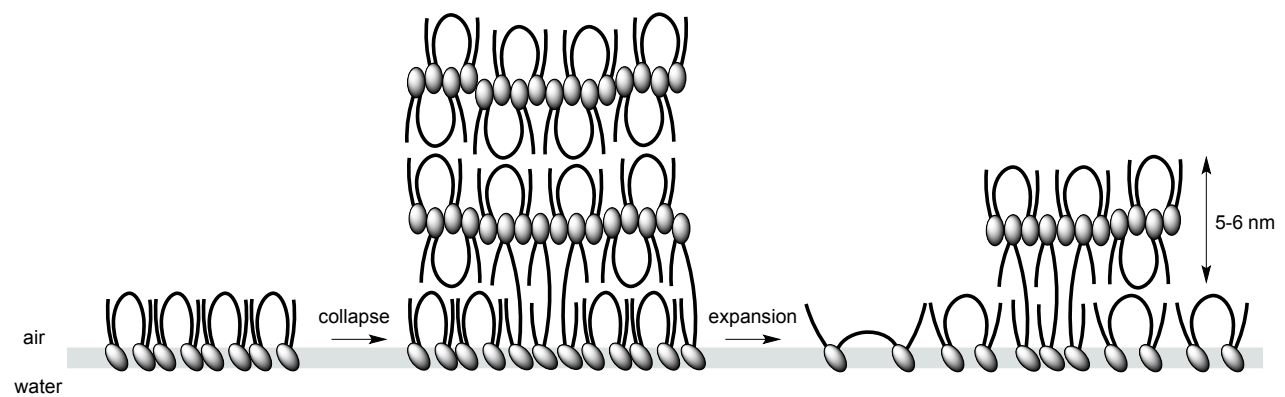

Fig. 9 Representation of the trans-tetraether lipid 4 films during collapse and expansion.

From a molecular point of view, the trans configuration of the cyclopentyl ring is compatible with a bent conformation of the lipids. However, even if it permits to keep the sugar residues into the aqueous phase, this conformation induces an important frustration within the hydrophobic domain. Indeed the lipid cannot undergo a high level of compression and consequently, during the collapse and the formation of multilayers, the slight free space between the two sugar moieties becomes available for a polar-head interdigitation and as soon as the lipid (5) has the possibility to adopt a less constrained stretched conformation it prefers to flip one polar head group towards the next layer. The cis-isomer has a higher conformational bias to orient the two alkyl chains towards the same direction favoring the bent conformation which is kept all along the compression at collapse.

\section{Conclusion}

The comparative study of diether (monopolar) and tetraether (bipolar) lipids was achieved by Langmuir and LangmuirBlodgett/AFM experiments. Whatever the polar head groups, all bipolar lipids studied here adopted a bent conformation during compressions of lipid films before limiting areas. It corresponds to a typical behavior of most of bipolar lipids.[12, 41, 42] However it is noteworthy that our synthetic bipolar glycolipids (lactosyl head groups) demonstrated abilities for the formation of highly stable multilayers. Indeed a very low surface pressure $\left(10 \mathrm{mN} \cdot \mathrm{m}^{-1}\right)$ was required to observe a significant disappearance of the multilayers. In addition to this original result we described also the effect of the variation of a single stereogenic centers on the conformation of these bipolar lipids. Therefore the stereochemistry of a cyclopentyl ring (cis or trans) placed in the middle of the hydrophobic domain of these bipolar glycolipids influenced the properties of the corresponding films. Before collapse it slightly influenced the compressibility of the lipid films. At collapse pressures the mechanisms of multilayer formation induced different molecular structuration. The trans isomer formed an interdigitated polar head group network and it partially adopted a stretched conformation at the interface. The cis-isomer preferred to keep a fully bent conformation within the multilayer organization and head to head interactions. These differences rely on the stereochemistry of the cyclopentyl ring itself inducing more or less rigidity to the whole hydrophobic domain. This research work complements other studies on the impact of cycolpentyl ring on lipid self-assembly,[52] adding insight into the impact of the stereochemistry of such carbocycle on bipolar lipid behaviors. Our results gather also useful information for the design of amphiphilic structures for the development of innovative self-assembled systems for application in drug delivery for instance. $[28,29]$

\section{Acknowledgment}


The Agence Nationale de la Recherche (ANR-09-JCJC-0034) is acknowledged for financial support and PhD grant to NT. The Région Bretagne is acknowledged for PhD grant to AJ. FEDER, « Fond Européen pour le Développement Régional» is acknowledged for financial support.

\section{Notes and references}

$†$ Electronic Supplementary Information (ESI) available: AFM images of samling taken during compression of tetraether 4,5; Phase and Amplitude AFM images of sampling taken during decompression of tetraether 4,5. See DOI: 10.1039/b000000x/

+ For a clear comparison of the rougness of the cis and trans-isomer samples, see phase AFM images in the ESI.

[1] A.P. Girard-Egrot, C.A. Marquette, L.J. Blum, Int. J. Nanotechnol., 7 (2010) 753-780.

[2] I. Czolkos, A. Jesorka, O. Orwar, Soft Matter, 7 (2011) 4562-4576.

[3] J.R. Siqueira, Jr., L. Caseli, F.N. Crespilho, V. Zucolotto, O.N. Oliveira, Jr., Biosens. Bioelectron., 25 (2010) $1254-1263$.

[4] D.P. Nikolelis, T. Hianik, G.-P. Nikoleli, Electroanalysis, 22 (2010) 2747-2763.

[5] A.P. Girard-Egrot, S. Godoy, L.J. Blum, Adv. Colloid Interface Sci., 116 (2005) 205-225.

[6] G. Puu, T. Tjaernhage, Recent Res. Dev. Anal. Biochem., 2 (2002) 217-227.

[7] N. Nuraje, H. Bai, K. Su, Prog. Polym. Sci., 38 (2013) 302-343.

[8] A. Meister, A. Blume, Adv. Planar Lipid Bilayers Liposomes, 16 (2012) 93-128.

[9] J.H. Fuhrhop, T. Wang, Chem. Rev., 104 (2004) 2901-2938.

[10] A. Meister, A. Blume, Curr. Opin. Colloid Interface Sci., 12 (2007) 138-147.

[11] G. Graf, S. Drescher, A. Meister, V.M. Haramus, B. Dobner, A. Blume, J. Colloid Interface Sci., 393 (2013) 143-150.

[12] J. Paczesny, P. Niton, A. Zywocinski, K. Sozanski, R. Holyst, M. Fialkowski, R. Kieffer, B. Glettner, C. Tschierske, D. Pociecha, E. Gorecka, Soft Matter, 8 (2012) 5262-5272.

[13] A. Meister, S. Drescher, G. Karlsson, G. Hause, U. Baumeister, G. Hempel, V.M. Garamus, B. Dobner, A. Blume, Soft Matter, 6 (2010) 1317-1324.

[14] D.P. Holland, A.V. Struts, M.F. Brown, D.H. Thompson, J. Am. Chem. Soc., 130 (2008) 4584-4585.

[15] A. Meister, M.J. Weygand, G. Brezesinski, A. Kerth, S. Drescher, B. Dobner, A. Blume, Langmuir, 23 (2007) 6063-6069.

[16] A. Meister, A. Blume, Curr. Opin. Colloid Interface Sci., 12 (2007) 138-147.

[17] G.S. Longo, D.H. Thompson, I. Szleifer, Biophys. J., 93 (2007) 2609-2621.

[18] M. Brard, C. Lainé, G. Réthoré, I. Laurent, C. Neveu, L. Lemiègre, T. Benvegnu, J. Org. Chem., 72 (2007) $8267-8279$.

[19] G. Réthoré, T. Montier, T. Le Gall, P. Delépine, S. Cammas-Marion, L. Lemiègre, P. Lehn, T. Benvegnu, Chem. Commun., (2007) 2054-2056.

[20] C. Lainé, E. Mornet, L. Lemiègre, T. Montier, S. Cammas-Marion, C. Neveu, N. Carmoy, P. Lehn, T. Benvegnu, Chem. Eur. J., 14 (2008) 8330-8340.

[21] M. Brard, W. Richter, T. Benvegnu, D. Plusquellec, J. Am. Chem. Soc., 126 (2004) 10003-10012.

[22] A. Jacquemet, V. Vié, L. Lemiègre, J. Barbeau, T. Benvegnu, Chem. Phys. Lipids, 163 (2010) 794-799.

[23] A. Jacquemet, L. Lemiègre, O. Lambert, T. Benvegnu, J. Org. Chem., 76 (2011) 9738-9747.

[24] A. Jacquemet, C. Mériadec, L. Lemiègre, F. Artzner, T. Benvegnu, Langmuir, 28 (2012) 7591-7597.

[25] S. Schouten, E.C. Hopmans, J.S. Sinninghe Damsté, Org. Geochem., 54 (2013) 19-61.

[26] P.L.-G. Chong, Chem. Phys. Lipids, 163 (2010) 253-265.

[27] A. Jacquemet, J. Barbeau, L. Lemiègre, T. Benvegnu, Biochimie, 91 (2009) 711-717.

[28] T. Benvegnu, L. Lemiègre, S. Cammas-Marion, Eur. J. Org. Chem., (2008) 4725-4744.

[29] J. Barbeau, S. Cammas-Marion, P. Auvray, T. Benvegnu, J. Drug Delivery, (2011) Article ID 396068, 396011pp.

[30] P. Dynarowicz-Łątka, A. Dhanabalan, O.N. Oliveira Jr, Adv. Colloid Interface Sci., 91 (2001) 221-293.

[31] B. Moghaddam, M.H. Ali, J. Wilkhu, D.J. Kirby, A.R. Mohammed, Q. Zheng, Y. Perrie, Int. J. Pharm., 417 (2011) $235-244$.

[32] Y.F. Dufrêne, G.U. Lee, Biochim. Biophys. Acta, Biomembr., 1509 (2000) 14-41.

[33] K. El Kirat, S. Morandat, Y.F. Dufrêne, Biochim. Biophys. Acta, Biomembr., 1798 (2010) 750-765.

[34] B. Berge, A. Renault, Europhys. Lett., 21 (1993) 773-778.

[35] R.M.A. Azzam, N.M. Bashara, Ellipsometry and Polarized Light, North-Holland, Amsterdam, 1977.

[36] G.L. Gaines, Insoluble monolayers at liquid-gas interfaces, Interscience Publishers, New-York, 1966.

[37] A. Lucero, M.R. Rodríguez Niño, A.P. Gunning, V.J. Morris, P.J. Wilde, J.M. Rodríguez Patino, J. Phys. Chem. B, 112 (2008) 76517661 .

[38] M. Pérez-Morales, J.M. Pedrosa, M.T. Martín-Romero, D. Möbius, L. Camacho, J. Phys. Chem. B, 108 (2004) $4457-4465$.

[39] S. Vidawati, J. Sitterberg, U. Rothe, U. Bakowsky, Colloids Surf., B, 87 (2011) 209-216.

[40] T. Kitano, T. Onoue, K. Yamauchi, Chem. Phys. Lipids, 126 (2003) 225-232.

[41] U. Bakowsky, U. Rothe, E. Antonopoulos, T. Martini, L. Henkel, H.J. Freisleben, Chem. Phys. Lipids, 105 (2000) $31-42$.

[42] A.P. Patwardhan, D.H. Thompson, Langmuir, 16 (2000) 10340-10350.

[43] C. Bottier, J. Géan, F. Artzner, B. Desbat, M. Pézolet, A. Renault, D. Marion, V. Vié, Biochim. Biophys. Acta, Biomembr., 1768 (2007) 1526-1540.

[44] J.L. Sorrells, F.M. Menger, J. Am. Chem. Soc., 130 (2008) 10072-10073.

[45] C. Jeworrek, F. Evers, M. Erlkamp, S. Grobelny, M. Tolan, P.L.-G. Chong, R. Winter, Langmuir, 27 (2011) 13113-13121.

[46] W.R. Schief, M. Antia, B.M. Discher, S.B. Hall, V. Vogel, Biophys. J., 84 (2003) 3792-3806.

[47] S. Rugonyi, E.C. Smith, S.B. Hall, Langmuir, 21 (2005) 7303-7307.

[48] T.E. Goto, L. Caseli, Langmuir, 29 (2013) 9063-9071.

[49] J. Saccani, S. Castano, F. Beaurain, M. Laguerre, B. Desbat, Langmuir, 20 (2004) 9190-9197.

[50] C. Ybert, W. Lu, G. Möller, C.M. Knobler, J. Phys. Chem. B, 106 (2002) 2004-2008.

[51] C. Ybert, W. Lu, G. Möller, C.M. Knobler, J. Phys.: Condens. Matter, 14 (2002) 4753

[52] P.L.-G. Chong, U. Ayesa, V. Prakash Daswani, E.C. Hur, Archaea, (2012) 1-11. 